\title{
Behaviour of Some Green Pepper Lines (Capsicum annuum l. Var. Grossum Sendt) Tested in the Comparative Plots for Evaluation at Research and Development Institute for Vegetable and Flower Growing Vidra
}

\author{
Gicuta SBIRCIOG* \\ Research and Development Institute for Vegetable and Flower Growing Vidra, 077185 \\ *coresponding author: ralldom@yahoo.com \\ Bulletin UASVM Horticulture 75(1) / 2018 \\ Print ISSN 1843-5262, Electronic ISSN 1843-536X \\ DOI:10.15835/buasvmcn-hort: 000218
}

\begin{abstract}
During the 2015-2016 periods in the frame of the experimental field of RDIVFG VIDRA, 5 round pepper lines, created at the Plant Breeding Department of the Institute were investigated under comparative plots for evaluation. As control the green pepper variety Galben superior was used. Several observations and morphological determinations were carried out aiming the following characteristics: total yield, number of fruits per plant, their shape and color. By comparison of the data regarding the total yield of the green pepper lines under investigation (average of the 2015-2016 period) one could notice that all the 5 lines assured a higher total yield to the control variety Galben superior. The values for total yield ranged between $51.8 \mathrm{t} / \mathrm{ha}$ and $52.5 \mathrm{t} / \mathrm{ha}$, by comparison with control variety Galben superior that gave $31.5 \mathrm{t} / \mathrm{h}$. The results emphasized that the best behaviour had the lines L45 by comparison with the control variety.
\end{abstract}

Keywords: breeding, green pepper, germoplasm, researches

\section{Introduction}

Green pepper represent one of the vegetable species of great importance for the mankind nutrition due to the high nutritional value of the fruit, namely by its high content in sugars and vitamins, especially in ascorbic acid (200$250 \mathrm{mg} / 100 \mathrm{~g}$ fresh product). Among the vegetable species cultivated in our country, the pepper plays an important role, having many uses (Sbîrciog, 2008, 2015). The pepper fruits are used for preparing a wide range of foods, they can be easily processed in the preservation industry or can be used for preparing the ground pepper. Some pepper species and varieties (Capsicum annuum L.) have a special decoration value and can be cultivated in pots, at home. The pepper fruits can be consumed fresh while presenting a great importance for their high nutrition value and the fact that the vitamins are wholly used by the human body (Sadia et al., 2017; Ciofu et al., 2003; Sbîrciog, 2012; Somos, 1984). The fruits' chemical composition is very complex. The content of $\mathrm{C}$ vitamin depends on the fruits' maturity degree, colour and size. On the world scale, there were and there are a great number of varieties and hybrids in green pepper assortment bread in the different parts of the world. But their differ it reaction of behavior in our local condition of our country and their introduction in our growing in a wise way, taking into account their ecological plasticity lead to the conclusion that it was and still remains the 
Table 1. The main characteristics and total yield of green pepper genotypes

\begin{tabular}{|c|c|c|c|c|c|c|}
\hline \multirow{2}{*}{ Cultivar } & \multirow{2}{*}{ Fruit shape } & \multirow{2}{*}{$\begin{array}{l}\text { Number of } \\
\text { fruits/ plant }\end{array}$} & \multicolumn{2}{|c|}{$\begin{array}{l}\text { Fruit color } \\
\text { In }\end{array}$} & \multirow{2}{*}{$\begin{array}{c}\text { Average } \\
\text { yield (t/ } \\
\text { ha) }\end{array}$} & \multirow{2}{*}{$\begin{array}{l}\text { Relative } \\
\text { yield (\%) }\end{array}$} \\
\hline & & & $\begin{array}{l}\text { Technological } \\
\text { stage }\end{array}$ & $\begin{array}{c}\text { Physiological } \\
\text { stage }\end{array}$ & & \\
\hline L45 & pyramidal & 12 & Green- yellowish & red & $52.5^{* * *}$ & 166.60 \\
\hline L63 & pyramidal & 10 & Green- yellowish & red & $51.8^{* * *}$ & 163.49 \\
\hline $\begin{array}{c}\text { Galben } \\
\text { superior } \\
\text { (control) }\end{array}$ & prismatic & 10 & White - yellowish & red & 31.5 & 100.00 \\
\hline LV10 & conical & 11 & Yellowish - white & red & $46.3^{* * *}$ & 149.98 \\
\hline L469 & pyramidal & 9 & Yellow - greenish & red & $37.8^{* *}$ & 120.00 \\
\hline L 106 & conical & 11 & Green-Yiellowish & red & $36.1^{*}$ & 114.60 \\
\hline
\end{tabular}

necessity for the development of the breeding works in green pepper in order to assure a national assortment specific for our country. Green pepper breeding nowadays aims mainly to obtain high productivity green pepper varieties and $\mathrm{F}_{1}$ hybrids having multiple disease resistance characterized by fruits of medium or big size of light color at the maturity for consumption-according to the consumer preferences from intense green color to ivory white color.

\section{Aims and objectives}

Researches were made during the period 2008-2016 at RIDVFG Vidra as part of the research topic and aimed at obtaining new pepper cultivars (types and hybrids), with superior productions as compared to the genotypes existing in the national assortment, resistant to the biotic and abiotic factors. The studies aimed at assessing the biological material obtained, in order to select the most valuable genotypes to be tested within the UPOV network.

\section{Materials and methods}

The research works carried out at RDIVFG Vidra during the 2015-2016 period in the frame of program green pepper breeding. The biological material was formed of five green pepper lines which were developed in the frame of the Institute were studied in the comparative plots for their behavior using as a control variety the cultivar Galben superior. The variants were set up in randomized blocks placed in four replication and during the growing season several observations and determination were performed according to
UPOV sheet. The germoplasm resources used in the frame of green pepper breeding process in order obtain of this material consisted in native and /or local populations as well as varieties and hybrids. As breeding methods bulk positive selection yearly resumed in the valuable populations, intraspecific pollination among valuable varieties and lines followed by the pedigree selection and bulk positive selection yearly repeated, until F7 generation, resumed in the advanced populations were used. During the vegetation period, various observations and biometrical determinations, according to the UPOV sheet, have been performed. The harvest and record of the yield were made in dynamics, by determining the total average yield ( $\mathrm{t} / \mathrm{ha}$ ) and relative yield (\%), in order to establish the production potential of the new green pepper genotypes. The production data were statistically processed by using the analysis of variance, while the level of significance of the production differences was established by means of the difference limit (Ciulca, 2002).

\section{Results and discussion}

By comparison of the data regarding the total yield of the green pepper lines under investigation (average of the 2015-2016 periods) one could notice that all the 5 lines assured a higher total yield to the control variety Galben superior. The values for total yield ranged between $51.8 \mathrm{t} / \mathrm{ha}$ in the line L63 and $52.5 \mathrm{t} /$ ha in the line L 45 and 35.1 in the line L106 by comparison with control variety Galben superior that gave $31.5 \mathrm{t} / \mathrm{ha}$. The differences of the yield among green pepper lines by the comparison with the variety Galben 
superior, were computed as statistically sure, they being characterized as very significant (L45, L3 and LV10) respectively significant - L106 (table 1).

The results shown in table 1 represent the average values of the two years of experiments. Among the genotypes under study, the L45 line for the field culture especially remarked itself by the pyramidal fruit, yielding 10-12 fruits per plant was particularly distinguished, being intended for consumption in fresh condition and for industrialization. The plant is vigorous (50-60 cm height) with pyramidal fruits, with an average weight of $150 \mathrm{~g}$, being green yellowish coloured before ripening and shiny intense red at the physiological maturity. The line L63 having large fruit of $140 \mathrm{~g}$ in light green colour is also remarkable. Considering the shape and fruit colour one could render evident the lines LV 10 and L469 having fruit of medium size (average weight $115 \mathrm{~g}$ ) characterized by light colours, well appreciated by consumers, of yellowish -white and yiellowish green respectively.

\section{Conclusion}

By this study carried out in 2015-2016 in the frame of a comparative crop plot for evaluation, regarding several green pepper lines developed at RDIVFG Vidra, one could conclude that all the lines recorded absolute values which were higher for the total yield than the control variety Galben superior, and on the other hand, the yield differences had a statistical significance. Regarding the total yield, one could emphasize the lines L 45 and $\mathrm{L} 63$ which gave a yield gain of 21 and $20.3 \mathrm{t}$ respectively by the comparison with the control variety Galben superior. The L45 line for the field culture was particularly distinguished, being intended for consumption in fresh condition and for industrialization. The plant is vigorous with pyramidal fruits, without pistil concavity, with an average weight of $150 \mathrm{~g}$, being green yellowish coloured before ripening and shiny intense red at the physiological maturity. The L45 line was submitted for testing within the UPOV network.

\section{References}

1. Ciofu R, Stan N, Popescu V, Pelaghia Chilom, Apahidean S, Horgoș A, Berar V. Lauer KF, Atanasiu N (2003). Tratat de legumicultură. Editura Ceres. București.

2. Ciulca S (2002). Tehnică experimentală. Editura Mirton. Timișoara.

3. Sadia Awalin, Mohammad Shahjajahan, Arjun Chondra Roy, Asma Akter, Mohammad Humayun Kabir (2017). Response of Bell Pepper (Capsicum annuum) to Foliar Feeding with Micronutrients and Shoot Pruning.JAERI. Doi: 10.9734/JAERI/2017/31620.

4. Sbîrciog Gicuța (2008). Behaviour of some Green Pepper Lines (Capsicum annuum L. var. grossum Sendt) Tested in the Comparative Plots for Evaluation. Lucrări ştiinţifice, Horticultura (USAMV București). Serie B- LI, p. 107-110.

5. Sbîrciog Gicuța (2012). New Pepper (Capsicum annuum L.) Genotypes Created at ICDLF Vidra. Bulletin of University of Agricultural Sciences and Veterinary Medicine ClujNapoca 69(1):425.

6. Sbîrciog Gicuța (2015). Behaviour of some Green Pepper Lines (Capsicum annuum L. var. grossum Sendt) Tested in the Comparative Plots for Evaluation. Bulletin of University of Agricultural Sciences and Veterinary Medicine Cluj-Napoca 72(1):225-226.

7. Somos A (1984). The Paprika. Akademiai Kiado, Budapest.

8. www.upov.int/edocs/tgdocs/en/tg076.pdf- Test Guidelines for Sweet Pepper - UPOV. 